DEPARTMENT OF ECONOMICS, MANAGEMENT AND STATISTICS

UNIVERSITY OF MILAN - BICOCCA

DEMS WORKING PAPER SERIES

Macroeconomic Conditions and Health: Inspecting the TransmissionMechanism

Emilio Colombo, Valentina Rotondi, Luca Stanca

No. 337 - May 2016

Dipartimento di Economia, Metodi Quantitativi e Strategie di Impresa Università degli Studi di Milano - Bicocca

http://dems.unimib.it/ 


\title{
Macroeconomic Conditions and Health: Inspecting the Transmission Mechanism
}

\author{
Emilio Colombo* Valentina Rotondi ${ }^{\dagger} \quad$ Luca Stanca $^{\ddagger}$
}

May 6, 2016

\begin{abstract}
This paper studies the effects of labor market conditions on individuallevel health, investigating the factors that moderate and mediate this relationship. Using a large and representative sample of individuals in Italy between 1993 and 2012, we shed light on the transmission mechanism, focusing on the role played by health behaviors (smoking, alcohol consumption, physical activity, eating habits) and economic stress. We find that, overall, higher local unemployment negatively affects health, with a dynamic response that differs across health conditions. Employment status and educational level play a significant role as moderators of these effects. Eating habits, in addition to economic stress, are found to play a key role in the transmission mechanism, while physical activity acts as a buffer against the adverse health effects of unemployment shocks.
\end{abstract}

Keywords: economic conditions, unemployment, health behaviors, health outcomes.

JEL codes: I1, I10, I12, I18

${ }^{*}$ Department of Economics Management and Statistics, University of Milan Bicocca. Email: emilio.colombo@unimib.it

${ }^{\dagger}$ Department of Management, Economics and Industrial Engineering, Politecnico di Milano. E-mail: valentina.rotondi@polimi.it

${ }^{\ddagger}$ Corresponding author. Department of Economics Management and Statistics, University of Milan Bicocca, Piazza dell'Ateneo Nuovo 1, 20126 Milan, Italy. E-mail: luca.stanca@unimib.it 


\section{Introduction}

The growing concerns about the pervasiveness and persistence of joblessness in advanced economies, and particularly in Europe, are fueled by the perception that the social costs of unemployment are far greater than the economic costs measured by reduced income levels. The World Health Organization (WHO) has forcefully warned policymakers against the adverse health consequences of the recent global financial crisis (WHO, 2009, 2011). Yet, the literature is still far from reaching a consensus about the effects of macroeconomic conditions on health outcomes. More importantly, relatively little is known about the transmission mechanism from aggregate economic fluctuations to individual health conditions.

Following the seminal work by Ruhm (2000), a number of studies have found a pro-cyclical pattern of mortality and chronic diseases, while other studies have found either counter-cyclical or a-cyclical patterns (Svensson, 2007; Charles and DeCicca, 2008; Stuckler et al., 2009). Moreover, these effects vary substantially by age group, gender, and type of health condition, and the results are generally sensitive to the specific indicators used to measure economic conditions (Stevens et al., 2015; Tekin, McClellan, and Minyard, 2013). To date, several papers have shown that weakening economies are associated with changes in either health outcomes, such as mortality (Edwards, 2008), heart attacks (Svensson, 2007) and mental disorders (Gili et al., 2013), or health behaviors, such as smoking (Ruhm, 2005), alcohol consumption (Ruhm and Black, 2002; Dee, 2001; Cotti, Dunn, and Tefft, 2015), lack of physical exercise and bad eating habits (Dave and Kelly, 2012). Given these broad effects, the challenge is to understand the underlying mechanisms linking macro-economic conditions to individual-level health (Xu, 2013).

The medical literature has identified several frameworks that underpin the relationship between economic conditions and health, such as the University of Michigan job stress model (Israel et al., 1996) and the Karasek's model (Karasek and Theorell, 1990; Karasek et al., 1998). In both these frameworks, the economic environment generates some stressors, that are either psychosocial (such as time pressure, uncertainty, job insecurity, etc.) or physical (heavy work-shifts, etc.). The exposure to such stressors generates perceived stress which, in turn, determines either physiological (e.g., heart attack) or psychological (e.g., anxiety, nervous disorders) negative health outcomes.

According to the medical literature, the most significant health problems directly related to stress are cardiovascular diseases (Belkic, Paul Landsbergis, and Baker, 2004; Kivimäki et al., 2006), nervous and mental disorders (Bonde, 2007; Netterstrom et al., 2008), diabetes (Heraclides et al., 2012), ulcer (Mayer, 
2000) and arthritis (Hassett and Clauw., 2010; Walker et al., 1999). Likewise, it is widely documented that risky health behaviors affect health. Lack of regular physical activity increases the risk of several chronic conditions, including coronary and hearth diseases (Warburton et al., 2010) and type 2 diabetes (Miller and Dunstan, 2004). Smoking increases substantially the risk of coronary and heart diseases, as well as respiratory conditions (US Department of Health and Human Services, 2014). Alcohol consumption is related with among others - cirrhosis, diabetes, heart and mental conditions (Rehm et al., 2009). Bad eating habits increase the risk of several chronic health conditions, as documented by WHO (2003).

From an economist's point of view, what is less clear is how these health behaviors are affected by aggregate economic conditions. On the one hand, bad economic conditions increase uncertainty about the future and trigger economic stress, altering the marginal costs and benefits of healthy behaviors (Catalano and Dooley, 1983); as a consequence, individuals may be induced to smoke more, consume more alcohol, or practice less physical activity. On the other hand, during recessions individuals experience a reduction (or expected reduction) in disposable income. As a consequence, alcohol consumption and smoking might fall. At the same time, during economic downturns the opportunity cost of time and, consequently, the opportunity cost of time-intensive activities, such as leisure, physical activity, household production and social relations, fall (Ruhm, 2000). Individuals who face a lower opportunity cost of leisure, may spend more time in health-improving activities, such as physical exercise, producing and consuming healthy meals, spending time in recreational activities and interpersonal relationships.

In this paper, we exploit detailed individual-level information about health behaviors and health conditions from the Multipurpose Survey on Households (ISTAT, 2015), together with data on local labor market conditions at NUTS3 level, to implement an identification strategy based on the variation over time and across provinces of local unemployment and individual health. Our study contributes to the existing literature in several respects. First, we provide evidence on the effects of macroeconomic conditions on health outcomes at individual level. Although the literature on macro-data is abundant, the evidence at micro level is more limited. In addition, while most existing studies focus on the static relationship between aggregate economic conditions and health, we take into account the fact that changes in economic conditions affect health outcomes over time. Second, we address explicitly the role played by individual characteristics as moderators, focusing on employment status, educational level and gender. Third, we provide a unified framework to identify the transmission mechanism from macroeconomic conditions to 
health outcomes, focusing on the role played by health behaviors and economic stress as mediators. We are thus able to disentangle the direct effects of macro-economic conditions from those mediated by health behaviors. This is a step forward with respect to the existing literature, which generally addresses the effects of local economic conditions on either health behaviors or health outcomes (e.g., Charles and DeCicca (2008), Ruhm (2000), Tekin, McClellan, and Minyard (2013), Contoyannis and Jones (2004)), thus failing to address the systemic nature of the relationship between economic conditions, health behaviors and health outcomes.

The paper is structured as follows. Sections 2 and 3 describe the data and methods, respectively. Section 4 presents the results. Section 5 concludes.

\section{Data}

We study the relationship between local labor market conditions and individuallevel health using repeated cross-section data from the Multipurpose Survey on Households, provided by the Italian National Institute of Statistics (ISTAT). The survey is conducted yearly since $1993^{1}$ on a representative sample of about 24,000 households, corresponding to 54,000 individuals, through face-to-face interviews. The data set contains detailed information about social behaviors, perceptions and time use in everyday life, in addition to individual and household characteristics.

We carry out our analysis by considering different measures of health status. More specifically, we consider self-reported measures of health. ${ }^{2}$ We start by considering indicators of general health. First, satisfaction with health, measured on a four-item ordinal scale (not at all, not much, enough, very much). We re-code this variable into two alternative binary variables: very dissatisfied with health conditions, equal to one if the respondent has chosen the first item of the scale, and dissatisfied with health conditions, equal to one if the respondent has chosen one of the first two items of the scale. Second, we consider three alternative indicators of hospitalization: first, a dummy variable indicating whether the subject has been recently in hospital; second, a variable measuring the number of times the subject has been in hospital; third, a variable measuring the total number of days in hospital. We

\footnotetext{
${ }^{1}$ The survey has not been implemented in 2004.

${ }^{2}$ Despite their limitations, there is common agreement in the literature that subjective health assessments are informative indicators of objective health conditions (Miilunpalo et al., 1997). However, people may tend to mis-report illnesses (Bound, 1991; Johnston, Propper, and Shields, 2009). Therefore, our estimates of the effects of economic conditions on health may be subject to attenuation bias, and should be viewed as conservative.
} 
also consider the presence of a number of specific chronic conditions: hypertension, infarct, angina, bronchial asthma, allergies, tumor, ulcer, liver stone, kidney stone, cirrhosis, arthritis, osteoporosis, and nervous disorders.

Regarding the transmission mechanism, we examine the role played as mediators by health behaviors commonly identified by the literature such as smoking (number of cigarettes per day), alcohol consumption (drink alcohol outside meals), physical inactivity (practicing no physical activity), and eating habits. We construct an index of diet variety as a weighted average of the type of food consumed, from a list of 12 different food items, with weights represented by the frequency of weekly consumption. The resulting index is recoded into a dummy variable with poor diet variety being equal to one when the index is lower than the median of the sample. Finally, we include among mediators a measure of economic stress, proxied by a dummy variable indicating dissatisfaction with respect to economic conditions (equal to one when the subjects reports to be dissatisfied or very dissatisfied with her own economic conditions).

Following the literature, we proxy economic conditions with local (provincelevel) unemployment rates. ${ }^{3}$ By using several waves of the Territorial Accounts by ISTAT, we were able to reconstruct the unemployment rate series at NUTS-3 level for 103 provinces from 1993 to 2012. Since the Italian territorial division at NUTS-3 level has changed during the period considered, we have reclassified provinces to 103 in order to have units consistent across the period considered. ${ }^{4}$ In order to focus on working-age adults that are still tied strongly to the labor force, we restrict the sample to individuals between the age of 18 and 66 , and further exclude from the analysis individuals who retired or are unable to work. This yields a final sample size of about 620,000 individuals. Table 1 provides summary statistics for the relevant variables.

\footnotetext{
${ }^{3}$ As a robustness check, when splitting the sample by gender, we also used gender-specific unemployment rates, obtaining qualitatively unchanged results.

${ }^{4}$ In principle, it would be possible to use alternative indicators of economic activity, such as GDP growth. However these indicators of real activity are not appropriate for our purposes for two main reasons: first, what matters most for individuals is the possibility of loosing (or not finding) a job, rather than the fact that GDP growth is high or low. In fact, local labor market conditions are likely to be crucial, particularly in a country like Italy, traditionally characterized by low labor market mobility. Second, the variability of GDP growth across provinces is much lower than that of unemployment, thus reducing the effectiveness of the identification strategy.
} 
Table 1: Descriptive statistics

\begin{tabular}{lccccc}
\hline Variable & Mean & Std. Dev. & Min. & Max. & N. Obs \\
\hline \hline Diabetes & 0.02 & 0.15 & 0 & 1 & 613861 \\
Hypertension & 0.09 & 0.29 & 0 & 1 & 614117 \\
Stroke & 0.01 & 0.09 & 0 & 1 & 612840 \\
Angina & 0.02 & 0.12 & 0 & 1 & 612966 \\
Asthma & 0.02 & 0.15 & 0 & 1 & 612814 \\
Allergy & 0.09 & 0.28 & 0 & 1 & 613516 \\
Tumor & 0.01 & 0.09 & 0 & 1 & 612574 \\
Ulcer & 0.03 & 0.18 & 0 & 1 & 612863 \\
Liver stone & 0.02 & 0.13 & 0 & 1 & 612765 \\
Cirrhosis & 0.00 & 0.05 & 0 & 1 & 612478 \\
Kidney stone & 0.02 & 0.14 & 0 & 1 & 612555 \\
Arthritis & 0.16 & 0.36 & 0 & 1 & 613974 \\
Osteoporosis & 0.03 & 0.18 & 0 & 1 & 612614 \\
Nervous disorders & 0.04 & 0.19 & 0 & 1 & 607068 \\
Smoking (heavy smoker) & 0.10 & 0.3 & 0 & 1 & 562868 \\
Alcohol (heavy drinker) & 0.06 & 0.23 & 0 & 1 & 574374 \\
Physically inactive & 0.37 & 0.48 & 0 & 1 & 477055 \\
Diet poor & 0.33 & 0.47 & 0 & 1 & 628148 \\
Economic stress & 0.46 & 0.5 & 0 & 1 & 565472 \\
Health satisfaction: low & 0.13 & 0.33 & 0 & 1 & 614897 \\
Health satisfaction: very low & 0.02 & 0.15 & 0 & 1 & 614897 \\
Been in hospital & 0.04 & 0.19 & 0 & 1 & 624015 \\
Times in hospital & 0.05 & 0.39 & 0 & 86 & 623900 \\
Days in hospital & 0.38 & 3.45 & 0 & 365 & 623288 \\
Unemployment (province) & 0.10 & 0.07 & 0.01 & 0.33 & 577383 \\
Gender & 0.49 & 0.50 & 0 & 1 & 577383 \\
Age & 42.09 & 12.8 & 18 & 66 & 577383 \\
Work: Employed & 0.60 & 0.49 & 0 & 1 & 577383 \\
Work: Student & 0.16 & 0.37 & 0 & 1 & 577383 \\
Work: Housewife & 0.05 & 0.21 & 0 & 1 & 577383 \\
Married & 0.64 & 0.48 & 0 & 1 & 577383 \\
Divorced & 0.02 & 0.13 & 0 & 1 & 577383 \\
Widowed & 0.03 & 0.17 & 0 & 1 & 577383 \\
Upper education & 0.37 & 0.48 & 0 & 1 & 577383 \\
Medium education & 0.46 & 0.50 & 0 & 1 & 577383 \\
Lower education & 0.17 & 0.37 & 0 & 1 & 577383 \\
\hline Nos Son & & & &
\end{tabular}

Notes: Source: Multipurpose Survey on Households (ISTAT, 2015). 


\section{Methods}

Our baseline specification relates individual health outcomes to province-level economic conditions, a set of individual-level controls, in addition to province and year fixed effects:

$$
H_{i p t}=\beta_{0}+\beta_{1} U_{p t-j}+X_{i p t} \Pi+\mu_{p}+\lambda_{t}+\varepsilon_{i p t}
$$

where $H_{i p t}$ denotes the health status of individual $i$ in region $p$ at time $t$, $U_{p t-j}$ is the unemployment rate in province $p$ at time $t-j, X$ is a vector of individual controls (marital status, education, age, gender, etc.), with coefficients denoted by $\Pi, \mu_{p}$ and $\lambda_{t}$ represent province and time (year) fixed effects, and $\varepsilon_{i p t}$ the individual-level disturbance term. Equation (1) is estimated for different lags of the province-level unemployment $(t, t-1, t-2, t-3)$, in order to allow for the possibility that changes in economic conditions affect health outcomes after some time.

The use of province-level unemployment rates ensures exogeneity with respect to individual-level health outcomes, while the inclusion of province fixed effects allows us to control for any unobservable time-invariant province-specific effects. Year fixed effects allow us to capture unobserved aggregate time effects or time trends. We estimate (1) using a linear probability model for three reasons. First, the SUR approach we employ for the estimation of the indirect effects of unemployment on health conditions, described below, is based on a linear model. Second, by using a linear model we avoid the difficulties associated to the interpretation of interaction effects (moderators) in nonlinear models. Third, the results are qualitatively unchanged when using probit or logit estimators. Standard errors are clustered at province level.

In order to investigate the transmission mechanism from economic conditions to health outcomes, we follow the approach by Preacher and Hayes (2008), illustrated in Figure 1. Economic conditions can affect health outcomes either directly (parameter $\gamma$ in the figure) or indirectly, through the mediator variables. We thus estimate the effect of economic conditions on the mediators (parameter $\alpha_{j}$ ) and the effect of mediators on health outcomes (parameter $\delta_{j}$ ). The indirect effect of economic conditions on health outcomes via mediator $j$ is obtained as the product of the two coefficients (i.e., $\alpha_{j} \delta_{j}$ ). Therefore, the total indirect effect of economic conditions is estimated as $\sum_{j} \alpha_{j} \delta_{j}$, and the total effect as the sum of the direct and indirect effects $\left(\gamma+\sum_{j} \alpha_{j} \delta_{j}\right)$.

Empirically, we implement a Seemingly Unrelated Regression (SUR) estimator, where point estimates and standard errors of combinations of parameters are computed using the Delta method, which provides an appropriate 
Figure 1: Effect of unemployment on health outcomes: the role of mediators

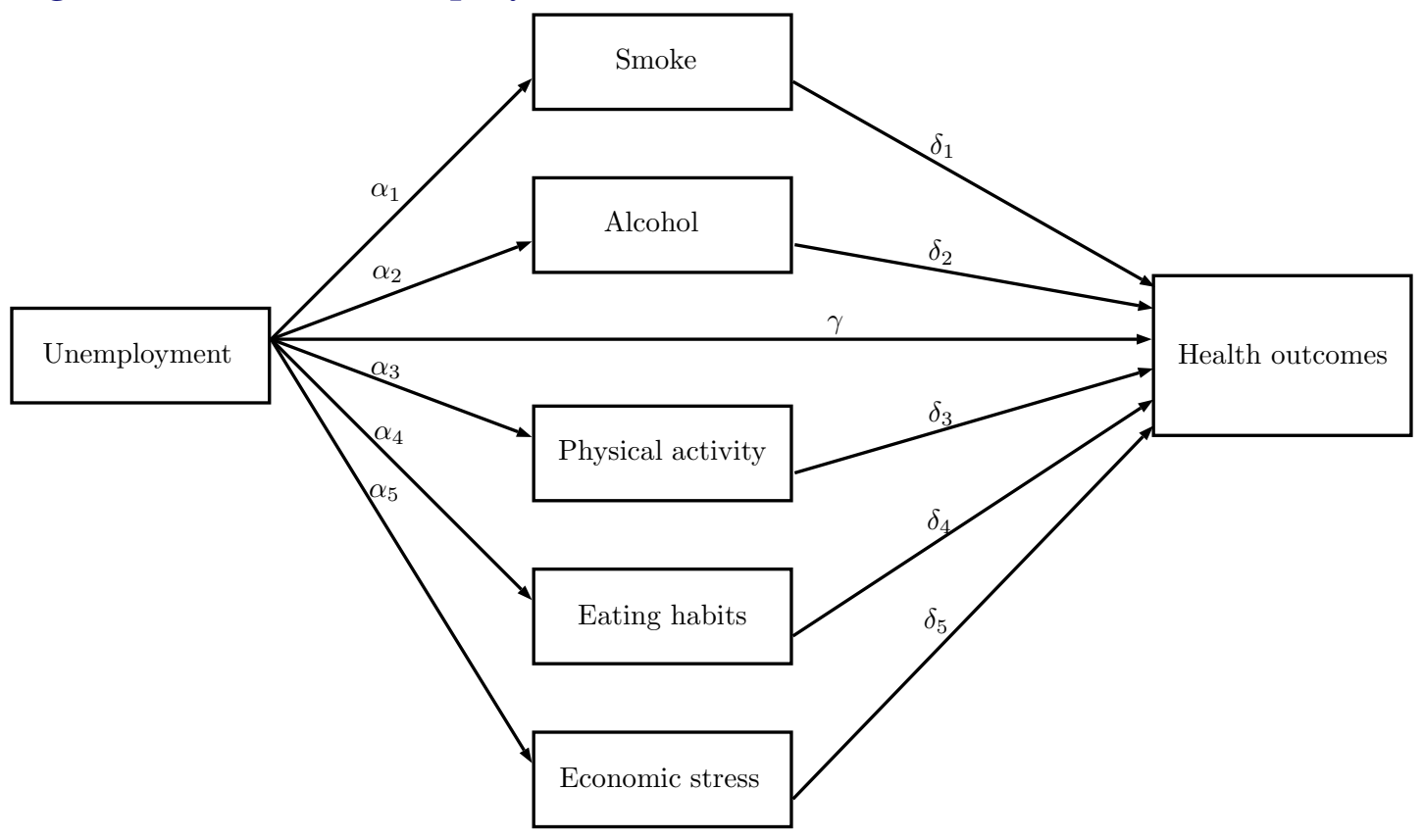

approximation in a large sample. ${ }^{5}$ As discussed above, we consider five mediators, each with a negative expected effect on health conditions: smoking, alcohol consumption, physical activity (lack of), eating habits (low diet variety) and economic stress.

\section{Results}

We start by characterizing the dynamic relationship between province-level unemployment and individual-level health outcomes. Next, we assess the role played by individual characteristics as moderators, focusing on employment status, educational level and gender. Finally, we examine the transmission mechanism from labor market conditions to health outcomes, focusing on the role played by a number of health behaviors as possible mediators, in addition to economic stress.

\footnotetext{
${ }^{5}$ The Delta method expands a function of a random variable around its mean, generally with a one-step Taylor approximation, and then computes the variance (Oehlert, 1992).
} 


\subsection{Local unemployment and health outcomes}

Table 2 presents estimation results for equation (1), using general health outcomes as dependent variables and different lags of the province-level unemployment rate as the key explanatory variables. Each cell reports, for a given health outcome, the estimated coefficient (and the standard error) of the unemployment rate $\left(U_{p t-j}\right)$. Province-level unemployment is positively and significantly related to the likelihood of being unsatisfied or very unsatisfied with health, and to the number of days of hospitalization. The size and significance of the relevant coefficients do not change substantially for different lags of unemployment. Province-level unemployment is also positively related to the probability of being hospitalized and to the number of times in hospital, although the estimated coefficients are not statistically significant.

Table 2: Unemployment and health outcomes

\begin{tabular}{llllll}
\hline & $U_{t}$ & $U_{t-1}$ & $U_{t-2}$ & $U_{t-3}$ & N.Obs Max/Min \\
\hline \hline Unsatisfied with health & $0.106^{*}$ & $0.110^{*}$ & 0.120 & $0.131^{*}$ & $565171-462596$ \\
& $(0.049)$ & $(0.053)$ & $(0.062)$ & $(0.053)$ & \\
Very unsat. with health & $0.023^{*}$ & $0.029^{*}$ & $0.033^{*}$ & 0.029 & $565171-462596$ \\
& $(0.011)$ & $(0.013)$ & $(0.016)$ & $(0.015)$ & \\
Been in hospital & 0.011 & 0.020 & 0.013 & 0.012 & $573562-470017$ \\
& $(0.013)$ & $(0.012)$ & $(0.014)$ & $(0.015)$ & \\
Hospital times & 0.009 & 0.030 & 0.034 & 0.023 & $573456-469893$ \\
& $(0.023)$ & $0.028)$ & $(0.018)$ & $(0.019)$ & \\
Hospital days & 0.244 & $0.373^{*}$ & $0.393^{* *}$ & $0.303^{*}$ & $572904-469581$ \\
& $(0.144)$ & $(0.153)$ & $(0.137)$ & $(0.149)$ & \\
\hline
\end{tabular}

Notes: Each cell reports the coefficient from regressions of individual's health outcomes on province-level unemployment at time $t, t-1, t-2, t-3$. Controls include gender, age, age squared, education, employment and occupation status, household characteristics, time dummies, province dummies. Standard errors clustered at province level. Minimum (maximum) number of observations refers to $U_{t-3}\left(U_{t}\right) .{ }^{*} p<0.05,{ }^{* *} p<0.01$

Table 3 reports estimation results for equation (1), using individual chronic health conditions as dependent variables. Worse local labor market conditions significantly increase the likelihood of reporting cardio-vascular disorders, such as hypertension, heart attack and angina. Higher unemployment is also positively and significantly related to the presence of diabetes, ulcer, arthritis, cirrhosis and nervous disorders. These results are consistent with findings in the literature (e.g., Lee et al., 2010; Svensson, 2007; Tapia Granados, 2008): on the one hand, we find evidence of a positive relation between local 
economic conditions and stress-related diseases; on the other hand, consistently with the theoretical predictions, we find no significant effects on chronic conditions that are not stress-related, such as allergies, liver and kidney stones and osteoporosis.

Interestingly, the lag structure of the effects of unemployment is consistent with the pattern that is outlined in the medical literature: while perceived stress has a positive contemporaneous effect on arthritis, cirrhosis and nervous disorders, the effects on circulatory conditions and diabetes are larger and statistically significant for higher lags of unemployment. The magnitude of the impact of local unemployment is consistent with the findings in the literature. For example, a one percentage point increase in the province-level unemployment rate is associated to a 0.03 per cent increase in the probability of experiencing asthma. Similarly, a one percentage point increase in the province unemployment rate is associated to a 0.06 per cent increase in the probability of experiencing nervous disorders.

The results in Tables 2 and 3 indicate that local labor market conditions affect health outcomes at different lags. A natural question to address is therefore whether we can identify a dynamic response of health outcomes following an unemployment shock. Tables 4 and 5 report the cumulative effects of unemployment on individual heath outcomes and conditions based on a fully dynamic model (i.e., the effects of a permanent shock to the unemployment rate). Although our setting is not ideal to perform such analysis, since at unemployment rates are strongly correlated from one year to another, the dynamic model generally confirms our previous results. Higher local unemployment negatively affects individual health outcomes, but only for longer lags.

\subsection{Employment status, education and gender as moderators}

There are several reasons to expect that the effects of province-level unemployment may differ across population sub-groups (Tekin, McClellan, and Minyard, 2013). Subjects whose current or expected employment status are more affected by labor market fluctuations are more likely to experience negative health effects (Charles and DeCicca, 2008). Therefore, we allow the estimated effect of local labor market conditions to vary across sub-samples defined on the basis of employment status (employed vs unemployed), education level (low vs high) and gender.

Employment status can moderate the effect of macro-economic fluctuations on individual-level health by altering the opportunity cost of time and the availability of economic resources (Ruhm, 2000). These two mechanisms, also referred to as the substitution and income effects of economic fluctua- 
Table 3: Unemployment and health conditions

\begin{tabular}{|c|c|c|c|c|c|}
\hline & $U_{t}$ & $U_{t-1}$ & $U_{t-2}$ & $U_{t-3}$ & N. Obs Max/Min \\
\hline \multirow[t]{2}{*}{ Diabetes } & 0.018 & $0.024^{*}$ & $0.029^{*}$ & $0.042^{* *}$ & $564342-461385$ \\
\hline & $(0.012)$ & $(0.012)$ & $(0.012)$ & $(0.010)$ & \\
\hline \multirow[t]{2}{*}{ Hypertension } & 0.010 & 0.022 & $0.068^{*}$ & $0.096^{* *}$ & $564552-461468$ \\
\hline & $(0.031)$ & $(0.030)$ & $(0.032)$ & $(0.029)$ & \\
\hline \multirow[t]{2}{*}{ Heart attack } & 0.007 & $0.011^{*}$ & $0.015^{* *}$ & $0.013^{*}$ & 563389-460422 \\
\hline & $(0.004)$ & $(0.004)$ & $(0.004)$ & $(0.006)$ & \\
\hline \multirow[t]{2}{*}{ Angina } & 0.013 & 0.015 & $0.020^{*}$ & 0.009 & 563504-460499 \\
\hline & $(0.008)$ & $(0.008)$ & $(0.008)$ & $(0.008)$ & \\
\hline \multirow[t]{2}{*}{ Asthma } & 0.032 & 0.025 & 0.023 & 0.025 & $563360-460400$ \\
\hline & $(0.016)$ & $(0.015)$ & $(0.017)$ & $(0.016)$ & \\
\hline \multirow[t]{2}{*}{ Allergy } & 0.030 & 0.035 & 0.043 & 0.034 & $564000-460998$ \\
\hline & $(0.037)$ & $(0.034)$ & $(0.031)$ & $(0.032)$ & \\
\hline \multirow[t]{2}{*}{ Tumor } & 0.003 & 0.001 & 0.005 & -0.006 & 563135-460182 \\
\hline & $(0.006)$ & $(0.006)$ & $(0.007)$ & $(0.006)$ & \\
\hline \multirow[t]{2}{*}{ Ulcer } & 0.028 & 0.029 & $0.058^{*}$ & $0.061^{* *}$ & $563410-460402$ \\
\hline & $(0.023)$ & $(0.022)$ & $(0.025)$ & $(0.023)$ & \\
\hline \multirow[t]{2}{*}{ Liver stones } & 0.016 & 0.011 & 0.018 & 0.016 & $563332-460336$ \\
\hline & $(0.013)$ & $(0.012)$ & $(0.014)$ & $(0.011)$ & \\
\hline \multirow[t]{2}{*}{ Cirrhosis } & $0.007^{*}$ & $0.008^{*}$ & $0.010^{* *}$ & $0.010^{* *}$ & $563058-460130$ \\
\hline & $(0.003)$ & $(0.003)$ & $(0.003)$ & $(0.003)$ & \\
\hline \multirow[t]{2}{*}{ Kidney stones } & 0.016 & 0.017 & 0.024 & 0.027 & $563126-460194$ \\
\hline & $(0.013)$ & $(0.014)$ & $(0.016)$ & $(0.019)$ & \\
\hline \multirow[t]{2}{*}{ Arthritis } & $0.165^{* *}$ & $0.160^{* *}$ & $0.208^{* *}$ & $0.203^{* *}$ & $564446-461340$ \\
\hline & $(0.050)$ & $(0.052)$ & $(0.066)$ & $(0.063)$ & \\
\hline \multirow[t]{2}{*}{ Osteoporosis } & -0.013 & -0.016 & 0.005 & 0.009 & $563183-460242$ \\
\hline & $(0.014)$ & $(0.015)$ & $(0.018)$ & $(0.019)$ & \\
\hline \multirow[t]{2}{*}{ Nervous dis. } & $0.058^{* *}$ & $0.052^{* *}$ & $0.080^{* *}$ & $0.066^{* *}$ & $558038-455072$ \\
\hline & $(0.019)$ & $(0.018)$ & $(0.025)$ & $(0.021)$ & \\
\hline
\end{tabular}

Note: Each cell reports the coefficient from regressions of individual health conditions on province-level unemployment at time $t, t-1, t-2, t-3$. Controls include gender, age, age squared, education, employment and occupation status, household characteristics, time dummies, province dummies. Standard errors clustered at province level. Minimum (maximum) number of observations refers to $U_{t-3}\left(U_{t}\right) .{ }^{*} p<0.05,{ }^{* *} p<0.01$ 
Table 4: Unemployment rate and health conditions: dynamic effects

\begin{tabular}{llllll}
\hline & $\begin{array}{l}\text { Unsat. } \\
\text { health }\end{array}$ & $\begin{array}{l}\text { Very unsat. } \\
\text { health }\end{array}$ & Hospital & $\begin{array}{l}\text { Hospital } \\
\text { times }\end{array}$ & $\begin{array}{l}\text { Hospital } \\
\text { days }\end{array}$ \\
\hline \hline$U_{t}$ & 0.076 & -0.008 & 0.007 & 0.041 & 0.361 \\
& $(0.074)$ & $(0.020)$ & $(0.024)$ & $(0.030)$ & $(0.228)$ \\
$U_{t-1}$ & 0.060 & 0.007 & 0.030 & 0.049 & 0.343 \\
& $(0.053)$ & $(0.016)$ & $(0.019)$ & $(0.027)$ & $(0.290)$ \\
$U_{t-2}$ & 0.088 & 0.023 & 0.014 & 0.042 & 0.264 \\
& $(0.073)$ & $(0.022)$ & $(0.018)$ & $(0.023)$ & $(0.175)$ \\
$U_{t-3}$ & $0.167^{*}$ & $0.033^{*}$ & 0.020 & $0.044^{*}$ & $0.452^{* *}$ \\
& $(0.069)$ & $(0.017)$ & $(0.017)$ & $(0.020)$ & $(0.138)$ \\
\hline$R^{2}$ & 0.06 & 0.02 & 0.01 & 0.00 & 0.01 \\
$\mathrm{~N}$. obs. & 462596 & 462596 & 470017 & 469893 & 469581 \\
\hline
\end{tabular}

Note: cumulative effects. Controls include gender, age, age squared, education, employment and occupation status, household characteristics, time dummies, province dummies.

Standard errors clustered at province level. ${ }^{*} p<0.05,{ }^{* *} p<0.01$

Table 5: Unemployment rate and health outcomes: dynamic effects

\begin{tabular}{llllllll}
\hline & Diabetes Hypert. & $\begin{array}{l}\text { Heart } \\
\text { att. }\end{array}$ & Ulcer & Cirrh. & Arthr. & $\begin{array}{l}\text { Nervous } \\
\text { d. }\end{array}$ \\
\hline \hline$U_{t}$ & -0.016 & -0.037 & -0.006 & 0.023 & $0.010^{*}$ & 0.088 & 0.059 \\
& $(0.021)$ & $(0.043)$ & $(0.011)$ & $(0.030)$ & $(0.004)$ & $(0.074)$ & $(0.030)$ \\
$U_{t-1}$ & 0.010 & -0.089 & -0.003 & -0.034 & 0.002 & 0.010 & 0.001 \\
& $(0.023)$ & $(0.049)$ & $(0.009)$ & $(0.023)$ & $(0.004)$ & $(0.067)$ & $(0.039)$ \\
$U_{t-2}$ & -0.010 & -0.026 & 0.012 & 0.027 & 0.005 & $0.161^{*}$ & $0.093^{* *}$ \\
& $(0.022)$ & $(0.057)$ & $(0.009)$ & $(0.035)$ & $(0.004)$ & $(0.080)$ & $(0.032)$ \\
$U_{t-3}$ & $0.040^{* *}$ & $0.072^{*}$ & $0.014^{*}$ & $0.063^{*}$ & $0.013^{* *}$ & $0.245^{* *}$ & $0.092^{* *}$ \\
& $(0.014)$ & $(0.033)$ & $(0.005)$ & $(0.029)$ & $(0.004)$ & $(0.073)$ & $(0.022)$ \\
\hline$R^{2}$ & 0.04 & 0.12 & 0.02 & 0.02 & 0.00 & 0.17 & 0.02 \\
N. obs. & 461385 & 461468 & 460422 & 460402 & 460130 & 461340 & 455072
\end{tabular}

Note: cumulative effects. Controls include: gender, age, age squared, education, employment and occupation status, household characteristics, time dummies, province dummies.

Reported standard errors clustered at province level. ${ }^{*} p<0.05,{ }^{* *} p<0.01$ 
tions on health, may have different signs, depending on individual-level employment status. During economic downturns, individuals who face lower opportunity costs of time, i.e., the unemployed, may spend more time in activities intended to improve their health, such as physical exercise, producing and consuming healthy meals, spending time in recreational activities and interpersonal relationships. At the same time, during recessions people make more effort to avoid losing their job. Thus, they may invest more time in working activity (if employed) or in job-search (if unemployed) and reduce, therefore, the time devoted to other non-market activities that would have had a positive effect on their health, e.g., physical exercise. Moreover, while the reduced availability of economic resources reduces investment in unhealthy habits, such as alcohol consumption and smoking, the resulting difficulty in coping with financial obligations triggers economic stress, which alters the marginal costs and benefits of healthy behaviors (Catalano and Dooley, 1983). ${ }^{6}$

Our hypothesis is that the income effect is low for an employed worker, since she is only marginally affected by macro-economic conditions. At the same time, the opportunity cost of her time is only marginally altered, since employment status is not directly affected by labor market fluctuations. What is affected by macro-economic conditions is, instead, her labor market prospects (i.e., a less intense work schedule, or the probability to lose the job), or the labor market prospects of her peers, that generate economic stress (Caroli and Godard, 2016). For the unemployed, we expect that the income effect is larger than for their employed counterparts. At the same time, unemployed individuals could have more leisure time than their employed counterparts, provided they do not fully devote it to job search activities. Regarding economic stress, two opposite factors are at play. On the one hand, for those who have already lost their job, worsening economic conditions do not increase the fear of joblessness. On the other hand, they reduce the likelihood of finding a new job.

Education has been shown to affect health behaviors and health outcomes (e.g., Brunello et al., 2015; Clark and Roayer, 2013; Conti, Heckman, and Urzua, 2010). In fact, while more educated workers are less at risk during economic downturns, thus weakening the stress channel (Charles and DeCicca, 2008), they are also more likely to avoid unhealthy behaviors, have a health insurance, and live in better neighborhoods (Lochner, 2011). Finally, given the literature on gender differences in health and labor market outcomes (e.g., Crimmins, Kim, and Solé-Auró, 2010; Van de Velde, Bracke, and Levecque, 2010; Seguino, 2010; Booth, Francesconi, and Frank, 2002), we expect women to be more at risk than men in the presence of worsening of economic conditions

\footnotetext{
${ }^{6}$ Catalano et al. (2011) identifies a further mechanism, namely, frustration-aggression. We refer the reader to their work for further explanations.
} 
(Hoynes, Miller, and Schaller, 2012).

We estimate equation (1) by adding among the predictors interaction terms between the moderator and each regressor (e.g., the product of the moderator and province-level unemployment rate). If a moderator effect is present, the interaction term in the regression model should be statistically significant. Table 6 reports the results, focusing on general health outcomes and the chronic health conditions which the medical literature reports as more closely linked to perceived stress and health behaviors. More specifically, we focus on cardiovascular conditions, diabetes, ulcer, cirrhosis, arthritis and nervous disorders.

Consistent with the theoretical predictions, the adverse effects of local unemployment on health conditions are, overall, significantly less strong for unemployed and highly educated individuals. Similar results are obtained when considering chronic health conditions. Gender does not appear to play a role as moderator when looking at general health conditions (e.g., Prause, Dooley, and Huh, 2009). However, the probability to experience diabetes and nervous disorders following economic downturns is lower for women than for men.

\subsection{Health behaviors and economic stress as mediators}

As shown in Figure 1, while a moderator can affect the strength and/or the direction of the relationship between labor market conditions and individuallevel health, a mediator variable explains how labor market conditions affect individual-level health. In other words, the mediator is in the middle of a causal chain linking aggregate economic conditions to individual-level health. This relationship is estimated using the methodology presented in Section 3, which allows us to disentangle the direct effect of macroeconomic fluctuations on health outcomes from the indirect effect through the mediators. More specifically, we focus on five mediators: smoking, alcohol consumption, physical inactivity, diet variety and economic stress.

First, we assess whether the selected health behaviors and economic stress qualify as potential mediators, by estimating the relationship between unemployment (at different lags) and each of these variables. Table 7 reports the results. Consistent with Charles and DeCicca (2008), and in contrast with Ruhm (2005), higher province-level unemployment is associated to a significant increase in smoking (except for $U_{t}$ ), with a stronger effect for longer time lags. Higher local unemployment is instead associated with a significant decrease in alcohol consumption (except for $U_{t-3}$ ), in line with the findings in Ruhm and Black (2002) and Johansson et al. (2006) and in contrast with Dee (2001). Interestingly, province-level unemployment is negatively associated with physical 
Table 6: Unemployment and health: moderators

\begin{tabular}{|c|c|c|c|c|}
\hline & $U_{t}$ & $U_{t-1}$ & $U_{t-2}$ & $U_{t-3}$ \\
\hline \multicolumn{5}{|c|}{ Unsatisfied with health } \\
\hline Employed & $-0.182^{* *}$ & $-0.214^{* *}$ & $-0.280^{* *}$ & $-0.280^{* *}$ \\
\hline High Education & $-0.199 * *$ & $-0.175^{* *}$ & $-0.139 *$ & -0.078 \\
\hline Female & -0.011 & 0.013 & 0.033 & 0.02 \\
\hline \multicolumn{5}{|l|}{ Hospital days } \\
\hline Employed & -0.327 & $-0.644^{*}$ & -0.458 & -0.458 \\
\hline High Education & -0.531 & -0.835 & $-0.772^{* *}$ & -0.213 \\
\hline Female & -0.16 & 0.023 & 0.142 & 0.157 \\
\hline \multicolumn{5}{|l|}{ Diabetes } \\
\hline Employed & -0.039 & $-0.042^{*}$ & $-0.068^{* *}$ & $-0.068^{* *}$ \\
\hline High Education & $-0.045^{* *}$ & $-0.052^{* *}$ & -0.010 & $-0.089 * *$ \\
\hline Female & -0.006 & -0.018 & $-0.048^{*}$ & -0.025 \\
\hline \multicolumn{5}{|l|}{ Hypertension } \\
\hline Employed & $-0.112^{* *}$ & $-0.102^{* *}$ & $-0.139 * *$ & $-0.139 * *$ \\
\hline High Education & -0.037 & -0.036 & -0.073 & -0.047 \\
\hline Female & -0.047 & -0.050 & -0.069 & -0.058 \\
\hline \multicolumn{5}{|l|}{ Heart attack } \\
\hline Employed & -0.010 & -0.011 & -0.014 & -0.014 \\
\hline High Education & -0.011 & -0.014 & $-0.052^{* *}$ & -0.009 \\
\hline Female & 0.008 & 0.012 & 0.004 & 0.003 \\
\hline \multicolumn{5}{|l|}{ Ulcer } \\
\hline Employed & 0.014 & 0.019 & -0.007 & -0.007 \\
\hline High Education & -0.013 & -0.019 & $-0.056^{*}$ & -0.044 \\
\hline Female & 0.018 & 0.03 & 0.025 & 0.022 \\
\hline \multicolumn{5}{|l|}{ Cirrhosis } \\
\hline Employed & 0.000 & 0.003 & -0.001 & -0.001 \\
\hline High Education & -0.009 & -0.010 & -0.013 & $-0.019 * *$ \\
\hline Female & -0.003 & -0.004 & -0.005 & -0.009 \\
\hline \multicolumn{5}{|l|}{ Arthritis } \\
\hline Employed & -0.092 & -0.068 & $-0.140^{*}$ & $-0.140^{*}$ \\
\hline High Education & -0.160 & -0.180 & $-0.217^{* *}$ & -0.101 \\
\hline Female & 0.022 & 0.045 & 0.014 & -0.011 \\
\hline \multicolumn{5}{|l|}{ Nervous disorders } \\
\hline Employed & $-0.061^{*}$ & -0.054 & $-0.138^{* *}$ & $-0.138^{* *}$ \\
\hline High Education & $-0.112^{* *}$ & $-0.113^{* *}$ & -0.074 & $-0.100^{* *}$ \\
\hline Female & -0.029 & -0.024 & $-0.088^{* *}$ & $-0.064^{* *}$ \\
\hline
\end{tabular}

Note: each cell reports differences by population sub-groups (employment status, education level, gender) for the effect of province-level unemployment at time $t, t-1, t-2, t-3$ on individual-level health conditions. For example, the coefficient for Employed reports the differential effect for employed of the effect of unemployment on the relevant health outcome. Controls include gender, age, age sduared, education, employment and occupation status, household characteristics, time dummies, province dummies. Standard errors clustered at province level. ${ }^{*} p<0.05,{ }^{* *} p<0.01$ 
inactivity (Ruhm, 2005; Colman and Dave, 2013, e.g.), while it is positively and significantly related to lack of diet variety (Dave and Kelly, 2012). Finally, higher local unemployment is positively and significantly related to economic stress (Caroli and Godard, 2016), with the only exception of $U_{t-3}$.

Table 7: Unemployment and health: mediators

\begin{tabular}{lllll}
\hline & $U_{t}$ & $U_{t-1}$ & $U_{t-2}$ & $U_{t-3}$ \\
\hline Smoking & 0.048 & $0.052^{*}$ & $0.061^{*}$ & $0.065^{* *}$ \\
& $(0.028)$ & $(0.025)$ & $(0.024)$ & $(0.024)$ \\
Alcohol consumption & $-0.053^{*}$ & $-0.058^{*}$ & $-0.056^{*}$ & -0.034 \\
& $(0.024)$ & $(0.024)$ & $(0.025)$ & $(0.024)$ \\
Physical inactivity & $-0.159^{*}$ & $-0.121^{*}$ & -0.079 & 0.059 \\
& $(0.062)$ & $(0.053)$ & $(0.066)$ & $(0.102)$ \\
Diet poor & $0.245^{* *}$ & $0.273^{* *}$ & $0.282^{* *}$ & $0.252^{* *}$ \\
Economic stress & $(0.078)$ & $(0.079)$ & $(0.085)$ & $(0.094)$ \\
& $0.338^{* *}$ & $0.286^{* *}$ & $0.186^{*}$ & 0.128 \\
& $(0.065)$ & $(0.072)$ & $(0.076)$ & $(0.071)$ \\
\hline
\end{tabular}

Note: Each cell reports the estimated effects of province-level unemployment at time $t, t-1$, $t-2, t-3$ on individual-level health behaviors. Controls include: gender, age, age squared, education, employment and occupation status, household characteristics, time dummies, province dummies. Standard errors clustered at province level. ${ }^{*} p<0.05$, ${ }^{* *} p<0.01$

Second, we estimate the direct and indirect effects of unemployment using a SUR estimator, as described in Figure 1. Table 8 reports the results. Each cell measures the indirect effect of unemployment on the relevant health outcome through each of the five mediators. The last two columns report the total indirect effect, i.e. the sum of the indirect effects of unemployment through each mediator $\left(\sum_{j=1}^{5} \alpha_{j} \delta_{j}\right.$ in Figure 1), and the direct effect $(\gamma$ in Figure 1). Note that, given the nature of our data set, we cannot account for the lagged effect of mediators on health outcomes, since our individual-level data is a repeated cross-section. Therefore, we account only for the lagged effects of unemployment on mediators, which are then assumed to have a contemporaneous effect on outcomes. ${ }^{\text {? }}$

For each of the health conditions under investigation, the indirect effect of unemployment through smoking (column 1) is not statistically significant. The indirect effect through alcohol consumption is positive and significant for dissatisfaction with health and for the presence of diabetes. Interestingly, the

\footnotetext{
${ }^{7}$ We only report the indirect effects of unemployment on selected health outcomes, i.e., those for which the link with health behaviors and economic stress is acknowledged by the medical literature.
} 
Table 8: Unemployment and health: transmission mechanism

\begin{tabular}{lccccccc}
\hline & $(1)$ & $(2)$ & $(3)$ & $(4)$ & $(5)$ & $(6)$ & $(7)$ \\
& Smoking & Alcohol & Phys. inact. & $\begin{array}{c}\text { Diet poor } \\
\text { Econ stress }\end{array}$ & $\begin{array}{c}\text { Total } \\
\text { Direct }\end{array}$ \\
\hline Unsat. health & 0.000 & $0.001^{*}$ & $-0.006^{*}$ & $0.005^{* *}$ & $0.037^{* *}$ & $0.038^{* *}$ & 0.080 \\
& $(0.000)$ & $(0.001)$ & $(0.002)$ & $(0.001)$ & $(0.007)$ & $(0.008)$ & $(0.047)$ \\
Hospital days & -0.001 & 0.004 & $-0.013^{*}$ & 0.002 & $0.023^{* *}$ & 0.015 & $0.394^{* *}$ \\
& $(0.001)$ & $(0.002)$ & $(0.005)$ & $(0.001)$ & $(0.005)$ & $(0.008)$ & $(0.097)$ \\
Diabetes & & & & & & & \\
& 0.000 & $0.000^{*}$ & $-0.001^{*}$ & 0.000 & $0.003^{* *}$ & $0.002^{* *}$ & 0.018 \\
Hypertension & $(0.000)$ & $(0.000)$ & $(0.000)$ & $(0.000)$ & $(0.001)$ & $(0.001)$ & $(0.016)$ \\
& -0.001 & 0.000 & -0.000 & $0.001^{* *}$ & $0.007^{* *}$ & $0.008^{* *}$ & 0.001 \\
Heart attack & $(0.000)$ & $(0.000)$ & $(0.000)$ & $(0.000)$ & $(0.001)$ & $(0.001)$ & $(0.032)$ \\
& -0.000 & 0.000 & -0.000 & $0.000^{* *}$ & $0.001^{* *}$ & $0.001^{* *}$ & 0.009 \\
Ulcer & $0.000)$ & $(0.000)$ & $(0.000)$ & $(0.000)$ & $(0.000)$ & $(0.000)$ & $(0.006)$ \\
& 0.001 & 0.000 & -0.000 & $0.001^{* *}$ & $0.004^{* *}$ & $0.006^{* *}$ & 0.028 \\
Cirrhosis & $(0.000)$ & $(0.000)$ & $(0.000)$ & $(0.000)$ & $(0.001)$ & $(0.001)$ & $(0.021)$ \\
& 0.000 & -0.000 & $-0.000^{*}$ & $0.000^{*}$ & $0.000^{* *}$ & $0.000^{* *}$ & $0.010^{* *}$ \\
Arthritis & $(0.000)$ & $(0.000)$ & $(0.000)$ & $(0.000)$ & $(0.000)$ & $(0.000)$ & $(0.003)$ \\
& 0.000 & -0.000 & -0.000 & 0.000 & $0.015^{* *}$ & $0.015^{* *}$ & $0.157^{* *}$ \\
Nervous dis. & $0.000)$ & $(0.000)$ & $(0.000)$ & $(0.000)$ & $(0.003)$ & $(0.003)$ & $(0.047)$ \\
& $(0.001$ & 0.000 & $-0.001^{*}$ & $0.001^{* *}$ & $0.006^{* *}$ & $0.007^{* *}$ & $0.060^{* *}$ \\
& $(0.000)$ & $(0.001)$ & $(0.000)$ & $(0.001)$ & $(0.002)$ & $(0.015)$ \\
\hline
\end{tabular}

Note: Each cell represents the effect of unemployment at time $t$ on each health outcome mediated by each health behavior and economic stress. Total: sum of all indirect effects. Controls include gender, age, age squared, education, employment and occupation status, household characteristics, time dummies, province dummies. SURE estimator, standard errors clustered at province level. ${ }^{*} p<0.05,{ }^{* *} p<0.01$

indirect effect of unemployment through physical inactivity is negative and significant for both dissatisfaction with health and days of hospitalization. It is also negative and significant for individual health conditions, such as diabetes, cirrhosis, and nervous disorders. These findings reflect the fact that, as shown in Table 7, when province-level unemployment rises, physical inactivity falls. The unemployment rate has a positive and significant indirect effect, through lower diet variety, on dissatisfaction with health and on each of the health conditions considered, with the only exception of diabetes and arthritis. Local unemployment has the strongest indirect effects on health outcomes through economic stress. The estimated indirect effects are negative, large and significant for both indicators of general health status, and for each of the health conditions considered.

The total indirect effect (column 6) is positive and strongly significant for dis-satisfaction with health and for each of the individual health conditions considered. The total indirect effect is generally smaller than the direct effect. 
Interestingly, however, the total indirect effect is about half the size of the direct effect in the case of dis-satisfaction with health, and it is even larger than the direct effect in the case of hypertension. Overall, the results suggest that health behaviors play a key role in the transmission mechanism explaining the relationship between labor market conditions and individual-level health outcomes. By negatively affecting eating habits and economic stress, worse local labor market conditions decrease satisfaction with health and significantly increase the likelihood of all the specific health conditions under investigation. On the other hand, worse local labor market conditions are associated with less physical inactivity which, in turn, reduces the likelihood of experiencing negative health conditions.

\section{Conclusions}

It is well know that macroeconomic fluctuations matter for individual-level health. This study sheds light on the underlying transmission mechanism. In order to design informed policy interventions aimed at offsetting the potentially harmful consequences of weakening economies, it is indeed more important to understand why and how, rather than just if, macroeconomic fluctuations affect health.

Following the approach by Preacher and Hayes (2008), we disentangled the direct and indirect effects of labor market conditions on health outcomes. Indirect effects were investigated by focusing on the mediating role played by a number of different health behaviors, such as smoking, alcohol consumption, physical inactivity, and poor diet, in addition to economic stress. The results indicate that higher province-level unemployment rate negatively affects health, while the dynamic response to unemployment shocks differs across health conditions: while unemployment has a contemporaneous effect on the presence of arthritis, cirrhosis and nervous disorders, the effects on circulatory diseases and diabetes become manifest only after two or three years.

Employment status and educational level play a significant role as moderators: the adverse effects of local unemployment on health conditions are, overall, significantly less strong for unemployed and highly educated individuals. In contrast, gender plays a minor role as moderator. As for the transmission mechanism, the negative relationship between local unemployment and health is mainly explained by eating habits (lack of diet variety) and economic stress (dissatisfaction with economic conditions). The effect of unemployment on health outcomes is instead partially offset by physical activity, since lack of physical exercise falls during recessions.

As in $\mathrm{Xu}$ (2013), our findings indicate that macroeconomic fluctuations 
have heterogeneous effects on time-intensive and income-intensive health behaviors. As a consequence, different health behaviors play different roles in mediating the effect of labor market conditions on health outcomes (Charles and DeCicca, 2008). The public policy implications of these findings are relevant. Interventions aimed at mitigating financial insecurity, by reducing exposure to economic stress, or at reducing the opportunity cost of time, may have different effects on the relationship between unemployment and health outcomes. 


\section{References}

Belkic, Karen, and Peter Schnall Paul Landsbergis, and Dean Baker. 2004. "Is job strain a major source of cardiovascular disease risk?" Scandinavian Journal of Work, Environment \& Health 30 (2):85-128.

Bonde, JP. 2007. "Psychosocial factors at work and risk of depression: a systematic review of the epidemiological evidence." Occupational \& Environmental Medicine 65 (7):438-445.

Booth, Alison L, Marco Francesconi, and Jeff Frank. 2002. “Temporary jobs: stepping stones or dead ends?” The economic journal 112 (480):F189-F213.

Bound, John. 1991. "Self-Reported Versus Objective Measures of Health in Retirement Models.” The Journal of Human Resources 26 (1):106-138.

Brunello, Giorgio, Margherita Fort, Nicole Schneeweis, and Rudolf WinterEbmer. 2015. "The causal effect of education on health: What is the role of health behaviors?" Health economics .

Caroli, Eve and Mathilde Godard. 2016. "Does job insecurity deteriorate health?" Health economics .

Catalano, Ralph and David Dooley. 1983. "The health effects of economic instability: A test of the economic stress hypothesis." In Influence of Economic Instability on Health. Springer, 225-262.

Catalano, Ralph, Sidra Goldman-Mellor, Katherine Saxton, Claire MargerisonZilko, Meenakshi Subbaraman, Kaja LeWinn, and Elizabeth Anderson. 2011. "The health effects of economic decline." Annual review of public health 32.

Charles, Kerwin Kofi and Philip DeCicca. 2008. "Local labor market fluctuations and health: is there a connection and for whom?" Journal of health economics 27 (6):1532-1550.

Clark, Damon and Heather Roayer. 2013. "The effect of education on adult mortality and health: Evidence from Britain." The American Economic Review 103 (6):2087-2120.

Colman, Gregory and Dhaval Dave. 2013. "Exercise, physical activity, and exertion over the business cycle." Social Science \& Medicine 93:11 - 20.

Conti, Gabriella, James Heckman, and Sergio Urzua. 2010. “The educationhealth gradient." The American economic review 100 (2):234. 
Contoyannis, Paul and Andrew M. Jones. 2004. "Socio-economic status, health and lifestyle." Journal of Health Economics 23 (5):965 - 995.

Cotti, Chad, Richard A Dunn, and Nathan Tefft. 2015. "The Dow is killing me: risky health behaviors and the stock market." Health economics 24 (7):803821.

Crimmins, Eileen M, Jung Ki Kim, and Aïda Solé-Auró. 2010. “Gender differences in health: results from SHARE, ELSA and HRS.” The European Journal of Public Health :ckq022.

Dave, Dhaval M and Inas Rashad Kelly. 2012. "How does the business cycle affect eating habits?” Social science \& medicine 74 (2):254-262.

Dee, Thomas S. 2001. "Alcohol abuse and economic conditions: Evidence from repeated cross-sections of individual-level data." Health economics 10 (3):257-270.

Edwards, Ryan D. 2008. "Who is hurt by procyclical mortality?" Social Science \& Medicine 67 (12):2051-2058.

Gili, Margalida, Miquel Roca, Sanjay Basu, Martin McKee, and David Stuckler. 2013. "The mental health risks of economic crisis in Spain: evidence from primary care centres, 2006 and 2010." The European Journal of Public Health 23 (1):103-108.

Hassett, Afton L and Daniel J Clauw. 2010. “The Role of Stress in Rheumatic Diseases.” Arthritis Research \& Therapy 12 (3).

Heraclides, Alexandros M, Tarani Chandola, Daniel R Witte, and Eric J Brunner. 2012. "Work Stress, Obesity and the Risk of Type 2 Diabetes: GenderSpecific Bidirectional Effect in the Whitehall II Study." Obesity 20 (2):428433.

Hoynes, Hilary, Douglas L. Miller, and Jessamyn Schaller. 2012. "Who Suffers during Recessions?” Journal of Economic Perspectives 26 (3):27-48.

Israel, Barbara A., Elizabeth A. Baker, Linda M. Goldenhar, and Catherine A. Heaney. 1996. "Occupational stress, safety, and health: Conceptual framework and principles for effective prevention interventions." Journal of occupational health psychology 1 (3):261-286.

ISTAT. 2015. "Multipurpose survey on households: aspects of daily life." Tech. rep., Italian National Institute of Statistics, http://www.istat.it/it/archivio/91926. 
Johansson, Edvard, Petri Böckerman, Ritva Prättälä, and Antti Uutela. 2006. "Alcohol-related mortality, drinking behavior, and business cycles." The European Journal of Health Economics 7 (3):212-217.

Johnston, David W., Carol Propper, and Michael A. Shields. 2009. "Comparing subjective and objective measures of health: Evidence from hypertension for the income/health gradient." Journal of Health Economics 28 (3):540 552.

Karasek, K. and T. Theorell. 1990. Health Work Stress: Productivity and the Reconstruction of Working Life. Basil Books.

Karasek, R., C. Brisson, N. Kawakami, I. Houtman, P Bongers, and B. Amick. 1998. "The Job Content Questionnaire (JCQ): an instrument for internationally comparative assessments of psychosocial job characteristics." Journal of Occupation Health Psychology 3 (4):322-55.

Kivimäki, Mika, Marianna Virtanen, Marko Elovainio, Anne Kouvonen, Ari Väänänen, and Jussi Vahtera. 2006. "Work Stress in the Etiology of Coronary Heart Disease - a Meta Analysis." Scandinavian Journal of Work, Environment \& Health 32 (6):431-442.

Lee, Sing, Wan-jun Guo, Adley Tsang, Arthur DP Mak, Justin Wu, King Lam Ng, and Kathleen Kwok. 2010. "Evidence for the 2008 economic crisis exacerbating depression in Hong Kong." Journal of affective disorders 126 (1):125-133.

Lochner, Lance. 2011. "Non-Production Benefits of Education: Crime, Health, and Good Citizenship. NBER Working Paper No. 16722.” National Bureau of Economic Research .

Mayer, EA. 2000. "The neurobiology of stress and gastrointestinal disease." Gut 47 (6):861-869.

Miilunpalo, Seppo, Ilkka Vuori, Pekka Oja, Matti Pasanen, and Helka Urponen. 1997. "Self-rated health status as a health measure: The predictive value of self-reported health status on the use of physician services and on mortality in the working-age population." Journal of Clinical Epidemiology 50 (5):517 -528 .

Miller, YD and DW Dunstan. 2004. "The effectiveness of physical activity interventions for the treatment of overweight and obesity and type 2 diabetes." Journal of Science and Medicine in Sport 7 (1):52-59. 
Netterstrom, Bo, Nicole Conrad, Per Bech, Per Fink, Ole Olsen, Reiner Rugulies, and Stephen Stansfeld. 2008. "The relation between work-related psychosocial factors and the development of depression." Epidemiological Review 118 (32).

Oehlert, Gary W. 1992. "A Note on the Delta Method." The American Statistician 46 (1):27-29.

Prause, JoAnn, David Dooley, and Jimi Huh. 2009. "Income volatility and psychological depression." American Journal of Community Psychology 43 (12):57-70.

Preacher, Kristopher J. and Andrew F. Hayes. 2008. "Asymptotic and resampling strategies for assessing and comparing indirect effects in multiple mediator models." Behavior Research Methods 40 (3):879-891.

Rehm, Jrgen, Colin Mathers, Svetlana Popova, Montarat Thavorncharoensap, Yot Teerawattananon, and Jayadeep Patra. 2009. "Global burden of disease and injury and economic cost attributable to alcohol use and alcohol-use disorders." The Lancet 373 (9682):2223 - 2233.

Ruhm, Christopher J. 2000. “Are Recessions Good For Your Health?” The Quarterly Journal of Economics 115 (2):617-650.

. 2005. "Healthy living in hard times." Journal of Health Economics $24(2): 341-363$.

Ruhm, Christopher J. and William E. Black. 2002. "Does drinking really decrease in bad times?” Journal of Health Economics 21 (4):659-678.

Seguino, Stephanie. 2010. "The global economic crisis, its gender and ethnic implications, and policy responses." Gender \& Development 18 (2):179-199.

Stevens, Ann H., Douglas L. Miller, Marianne E. Page, and Mateusz Filipski. 2015. "The Best of Times, the Worst of Times: Understanding Pro-cyclical Mortality.” American Economic Journal: Economic Policy 7 (4):279-311.

Stuckler, David, Sanjay Basu, Marc Suhrcke, Adam Coutts, and Martin McKee. 2009. "The public health effect of economic crises and alternative policy responses in Europe: an empirical analysis.” Lancet 374:315-323.

Svensson, Mikael. 2007. "Do not go breaking your heart: Do economic upturns really increase heart attack mortality?” Social Science \& Medicine 65 (4):833 -841 . 
Tapia Granados, Josè. 2008. "Macroeconomic fluctuations and mortality in postwar Japan.” Demography 45 (2):323-343.

Tekin, Erdal, Chandler McClellan, and Karen Jean Minyard. 2013. "Health and Health Behaviors during the Worst of Times: Evidence from the Great Recession." Working Paper 19234, National Bureau of Economic Research.

US Department of Health and Human Services. 2014. "The Health Consequences of Smoking: 50 Years of Progress: A Report of the Surgeon General." Tech. rep., US Department of Health and Human Services, Centers for Disease Control and Prevention,.

Van de Velde, Sarah, Piet Bracke, and Katia Levecque. 2010. "Gender differences in depression in 23 European countries. Cross-national variation in the gender gap in depression." Social Science \& Medicine 71 (2):305-313.

Walker, J. G., G. O. Littlejohn, N. E. McMurray, and M. Cutolo. 1999. "Stress system response and rheumatoid arthritis: a multilevel approach." Rheumatology 38 (11):1050-1057.

Warburton, DE, Sarah Charlesworth, Adam Ivey, Lindsay Nettlefold, and SS Bredin. 2010. "A systematic review of the evidence for Canadas Physical Activity Guidelines for Adults." Int J Behav Nutr Phys Act 7 (1):39.

WHO. 2003. "Diet, Nutrition and the Prevention of Chronic Diseases." Tech. rep., WHO.

- 2009. "The Financial Crisis and Global Health, Report of a High-Level Consultation." Tech. rep., who.

—. 2011. "Impact of Economic Crises on Mental Health." Tech. rep., WHO.

Xu, Xin. 2013. "The business cycle and health behaviors." Social Science \& Medicine 77:126 - 136. 